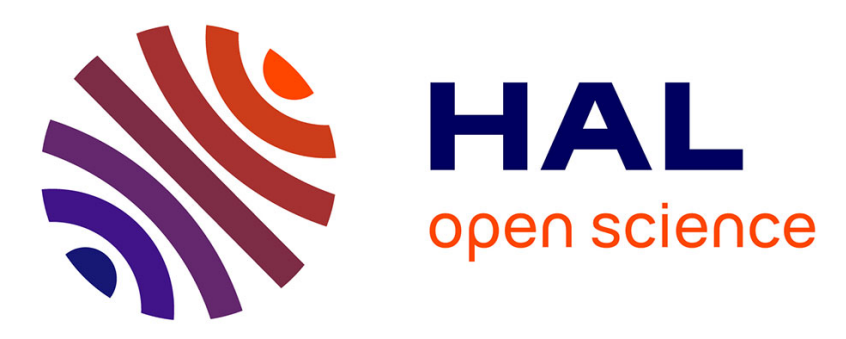

\title{
Single-scan multidimensional NMR analysis of mixtures at sub-millimolar concentrations by using SABRE hyperpolarization
}

Valeria Daniele, François-Xavier Legrand, Patrick Berthault, Jean-Nicolas Dumez, Gaspard Huber

\section{To cite this version:}

Valeria Daniele, François-Xavier Legrand, Patrick Berthault, Jean-Nicolas Dumez, Gaspard Huber. Single-scan multidimensional NMR analysis of mixtures at sub-millimolar concentrations by using SABRE hyperpolarization. ChemPhysChem, 2015, 16, pp.3413-3417. 10.1002/cphc.201500535 . hal01228706

\section{HAL Id: hal-01228706 \\ https://hal.science/hal-01228706}

Submitted on 20 Oct 2021

HAL is a multi-disciplinary open access archive for the deposit and dissemination of scientific research documents, whether they are published or not. The documents may come from teaching and research institutions in France or abroad, or from public or private research centers.
L'archive ouverte pluridisciplinaire HAL, est destinée au dépôt et à la diffusion de documents scientifiques de niveau recherche, publiés ou non, émanant des établissements d'enseignement et de recherche français ou étrangers, des laboratoires publics ou privés. 


\title{
Single-scan multidimensional NMR analysis of mixtures at sub- millimolar concentrations using SABRE hyperpolarization
}

\author{
Valeria Daniele, ${ }^{[\mathrm{a}]}$ François-Xavier Legrand,${ }^{[\mathrm{b}]}$ Patrick Berthault, ${ }^{[\mathrm{a}]}$ Jean-Nicolas Dumez ${ }^{*[\mathrm{c}]}$ and Gaspard \\ Huber*[a]
}

Abstract: Signal amplification by reversible exchange (SABRE) is a promising method to increase the sensitivity of nuclear magnetic resonance (NMR) experiments. However, SABRE-enhanced NMR ${ }^{1} \mathrm{H}$ signals are short-lived and SABRE is often used to record $1 \mathrm{D}$ NMR spectra only. When the sample of interest is a complex mixture, this results in severe overlaps for ${ }^{1} \mathrm{H}$ spectra. In addition, the use of a co-substrate, whose signals may obscure ${ }^{1} \mathrm{H}$ spectra, is today the most efficient way to lower the detection limit of SABRE experiments. Here we describe an approach to obtain clean, SABREhyperpolarized $2 \mathrm{D}^{1} \mathrm{H}$ NMR spectra of mixtures of small molecules at sub-millimolar concentrations in a single scan. The method relies on the use of para-hydrogen together with a deuterated co-substrate for hyperpolarization and ultrafast 2D NMR for acquisition. It is applicable to all substrates that can be polarized with SABRE.

\section{Introduction}

Nuclear magnetic resonance is a very powerful but particularly insensitive analytical technique. Hyperpolarization techniques aim at improving its sensitivity by increasing the population difference between nuclear spin states far beyond the Boltzmann value. One of these techniques, Para-Hydrogen Induced-Polarization (PHIP), ${ }^{[1-3]}$ relies on the total spin alignment of parahydrogen $\left(\mathrm{p}-\mathrm{H}_{2}\right)$ molecules, which can be generated with no need for an expensive and complex apparatus. $^{[4,5]}$ Signal Amplification By Reversible Exchange (SABRE) is a promising PHIP method ${ }^{[6,7]}$ based on the reversible binding of parahydrogen and the substrate of interest to a metal center, usually an iridium complex: the resulting transient coupling network can transfer the spin order of $\mathrm{p}-\mathrm{H}_{2}$ to the nuclear spins of the substrate where observable polarization is formed. ${ }^{[8]}$ This method has the potential to vastly broaden the application field of parahydrogen-based hyperpolarization, since it does not require the existence of an analogue of the substrate of interest containing unsaturated bonds. It has for example been applied to two drugs, pyrazinamide and isoniazid, used in

[a] Dr. V. Daniele, Dr. P. Berthault, Dr. G. Huber

Laboratoire Structure et Dynamique par Résonance Magnétique IRAMIS/NIMBE - UMR 3685 CEA/CNRS

CEA - Saclay

91191 Gif sur Yvette, France

E-mail: gaspard.huber@cea.fr

[b] Dr. F.-X. Legrand

Institut Galien-Paris Sud, UMR CNRS 8612,

Faculté de Pharmacie, Univ. Paris-Sud

5 rue Jean-Baptiste Clément, 92290 Châtenay-Malabry, France

[c] Dr. J.-N. Dumez

Institut de Chimie des Substances Naturelles - CNRS UPR2301,

Avenue de la Terrasse

91190 Gif-sur-Yvette, France.

E-mail: jeannicolas.dumez@cnrs.fr

Supporting information for this article is given via a link at the end of the document. the treatment of tuberculosis. ${ }^{[9]}$ It has also been applied to nicotinamide which acts as an active microbial agent against Mycobacterium tuberculosis and Human Immunodeficiency Virus. ${ }^{[10]}$

In the first SABRE experiments, a rather high substrate concentration, in the millimolar range, was necessary to observe optimal hyperpolarized signals for the free substrate: at low concentration the solvent may compete with the substrate on the catalyst. This limitation has been overcome by the addition of a concentrated co-substrate, ${ }^{[11]}$ i.e. a suitable ligand which can enter the coordination sphere of the metal center. In separate studies, the use of a deuterated co-substrate has been shown to yield higher signal enhancement factors. ${ }^{[12,13]}$ The SABRE technique has also been applied to the quantitative analysis of a dilute molecule in a complex mixture: in this case, the other molecules in the mixture, which are in large excess, act as cosubstrates. ${ }^{[14]}$

One-dimensional ${ }^{1} \mathrm{H}$ NMR spectra of complex mixtures, however, typically suffer from extensive overlap and may not be sufficient for analytical purposes. ${ }^{[15]}$ The spectral overlap problem is even more acute when a concentrated co-substrate is used, owing to the very intense signals of the co-substrate itself. Multidimensional $(\mathrm{nD}) \mathrm{NMR}$ spectra are often essential for the analysis of mixtures, but the short-lived nature of hyperpolarized signals - mainly determined by their longitudinal relaxation times - is not compatible with conventional approaches of multidimensional NMR. One possibility is the use of ultrafast NMR, which yields $\mathrm{nD}$ spectra in a single scan ${ }^{[16,17]}$ and is becoming a powerful analytical tool. ${ }^{[18,19]}$ The ultrafast COSY pulse sequence has been used to detect parahydrogenbased hyperpolarization of quinoline at $10 \mathrm{mM} .^{[20,21]}$

In this article, we describe an approach to obtain clean, SABRE-hyperpolarized 1D and ultrafast 2D NMR of mixtures of small molecules at sub-millimolar concentrations. We first show that the use of a deuterated co-substrate virtually suppresses unwanted intense signals of the co-substrate itself, thus simplifying the NMR spectra, particularly those of sample mixtures. Then, we illustrate the use of ultrafast $2 \mathrm{D}$ in combination with a deuterated co-substrate to detect a substrate at sub-millimolar concentrations. Finally, we show how the proposed approach can help in the analysis of a complex mixture of small molecules.

\section{Results and Discussion}


When molecules of interest have a total concentration of less than 3 times the catalyst concentration, addition of a cosubstrate to the sample is necessary to achieve significant hyperpolarization with current SABRE catalysts. ${ }^{[11]}$ An example of this approach, the hyperpolarization of 4,4'-bipyridyl (bpy, Fig. 1 ), is shown in Figure 2. These spectra were obtained on a dilute solution of the substrate bpy $\left(\mathrm{C}_{s}=0.5 \mathrm{mM}\right.$, which means $0.25 \mu \mathrm{mol}$ in the NMR tube), in the presence of the metal complex precursor $[\operatorname{Ir}(\mathrm{COD})(\mathrm{IMes}) \mathrm{Cl}]\left(\mathbf{1}, \mathrm{C}_{\mathrm{M}}=0.13 \mathrm{mM}\right)$ and pyridine (either standard or perdeuterated) as a co-substrate $\left(\mathrm{C}_{\mathrm{C}}\right.$ $=10 \mathrm{mM}$ ). Perdeuterated pyridine is a commercially available molecule, widely used as a solvent for NMR. Activation of complex precursor 1 by molecular hydrogen leads to the formation of several possible metal complexes of the formula $\left[\operatorname{Ir}(\mathrm{IMes})(\mathrm{H})_{2}\left(\mathrm{~S}_{\mathrm{i}}\right)\left(\mathrm{S}_{\mathrm{j}}\right)\left(\mathrm{S}_{\mathrm{k}}\right)\right] \mathrm{Cl}(\mathbf{2})$ where i, j and $\mathrm{k}$ are either the substrate or the co-substrate. ${ }^{[22]}$ After degassing the NMR tube, fresh $51 \%$-enriched $\mathrm{p}-\mathrm{H}_{2}$, prepared at liquid nitrogen temperature, was introduced and the tube was shaken at $7 \mathrm{mT}$, in the fringe field of the spectrometer, then quickly introduced into the spectrometer magnet. Comparison of Fig. 2a and 2c shows that the signal of o-py (abbreviations in Fig. 1) is enhanced by a factor ca. 900 . However, it is obvious in Fig. 2c that the intense signal of the hyperpolarized co-substrate is detrimental for the analysis of the molecule of interest, as it obscures the peak corresponding to the beta protons of bpy (see Table S1 for chemical shifts). In contrast, the spectra shown in Fig. $2 b$ and $2 d$ were obtained using deuterated pyridine as a co-substrate, deuteration rate being measured at $99.5,99.3$ and $99.0 \%$ at ortho, meta and para positions, respectively. In this case, the two signals of bpy can be observed. In particular, b-bpy can be distinguished from residual protonated p-py signal. Hence, deuteration of the co-substrate removes the need to find a co-substrate with adequate chemical shifts, which would not overlap with those of the molecules of interest. This is only partly true for pyridine, as a ${ }^{1} \mathrm{H}$ signal is still observed for the ortho positions. This may be explained by the fact that iridium(I) complexes such as $\mathbf{2}$ are known to catalyze ortho-directed hydrogen isotope exchange. ${ }^{[23-25]}$<smiles>CN1C=CN(S(C)(=O)=O)N1CC1CC2CCC1C2</smiles>

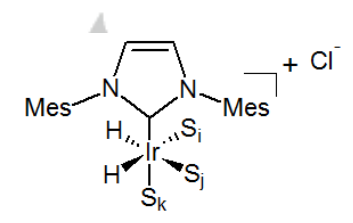
1<smiles>c1cc(-c2ccncc2)ccn1</smiles>

bpy<smiles>c1ccccc1</smiles>

py<smiles>NC(=O)c1cccnc1</smiles>

ni<smiles>CCc1cccnc1</smiles><smiles>CCc1ccccn1</smiles>

2-epy<smiles>CN(C)C(=O)c1cccnc1</smiles>
dmni<smiles>CCc1ccncc1</smiles>
4-epy
Figure 1. Structures and nomenclature of the complex precursor 1, the activated complex 2, the co-substrate and substrates used in this study. The abbreviations indicate: 4,4'-bipyridyl (bpy), pyridine (py), nicotinamide (ni), $\mathrm{N}, \mathrm{N}$-dimethylnicotinamide (dmni), 2-ethylpyridine (2-epy), 3-ethylpyridine (3epy) and 4-ethylpyridine (4-epy).

Using a deuterated co-substrate can also have advantages in terms of sensitivity, in addition to yielding a cleaner spectrum. First, a higher receiver gain may be used in the absence of strong signals from the co-substrate. Then, a deuterated cosubstrate can improve the enhancement factor for the substrate. ${ }^{[12,13]}$ In particular, for the alpha protons of bpy (noted a-bpy in Fig. 1), the enhancement factor increases from 86-fold in the presence of protonated pyridine (py) to 140 in the presence of deuterated pyridine (py- $\left.d_{5}\right)$. This higher enhancement is a consequence of the fact that polarization is not efficiently transferred into the ${ }^{2} \mathrm{H}$-nuclei of the deuterated ligand, because of the greatly reduced hydride- ${ }^{2} \mathrm{H}$ J-couplings compared to the hydride- ${ }^{1} \mathrm{H} \mathrm{J}$-couplings and their frequency difference.

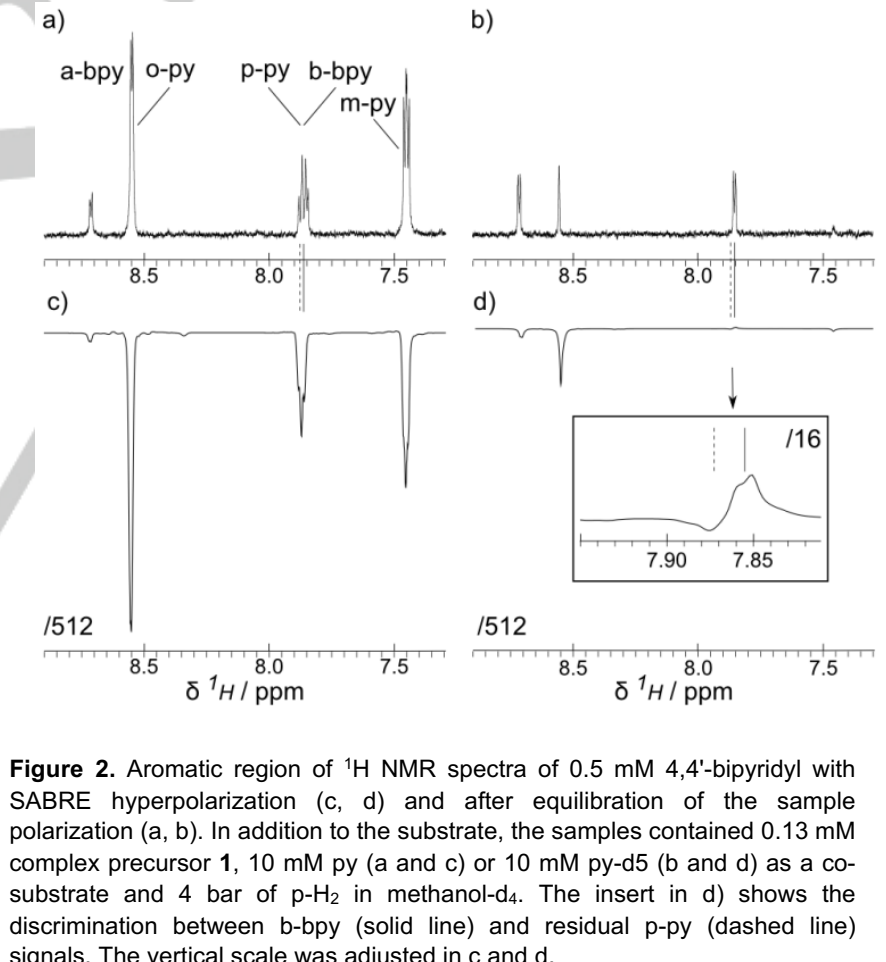
signals. The vertical scale was adjusted in $\mathrm{c}$ and $\mathrm{d}$.

One-dimensional ${ }^{1} \mathrm{H}$ NMR may not be sufficient to identify or quantify analytes in a complex mixture. Ultrafast 2D COSY spectra can be obtained in a single scan with a COSY pulse sequence using continuous spatial encoding. ${ }^{[26]}$ Figure 3 shows an ultrafast COSY spectrum recorded after SABRE hyperpolarization of bpy (see Experimental Section and Fig. S1 for details of the sequence). The use of a co-substrate here makes it possible to observe a good-quality spectrum of a

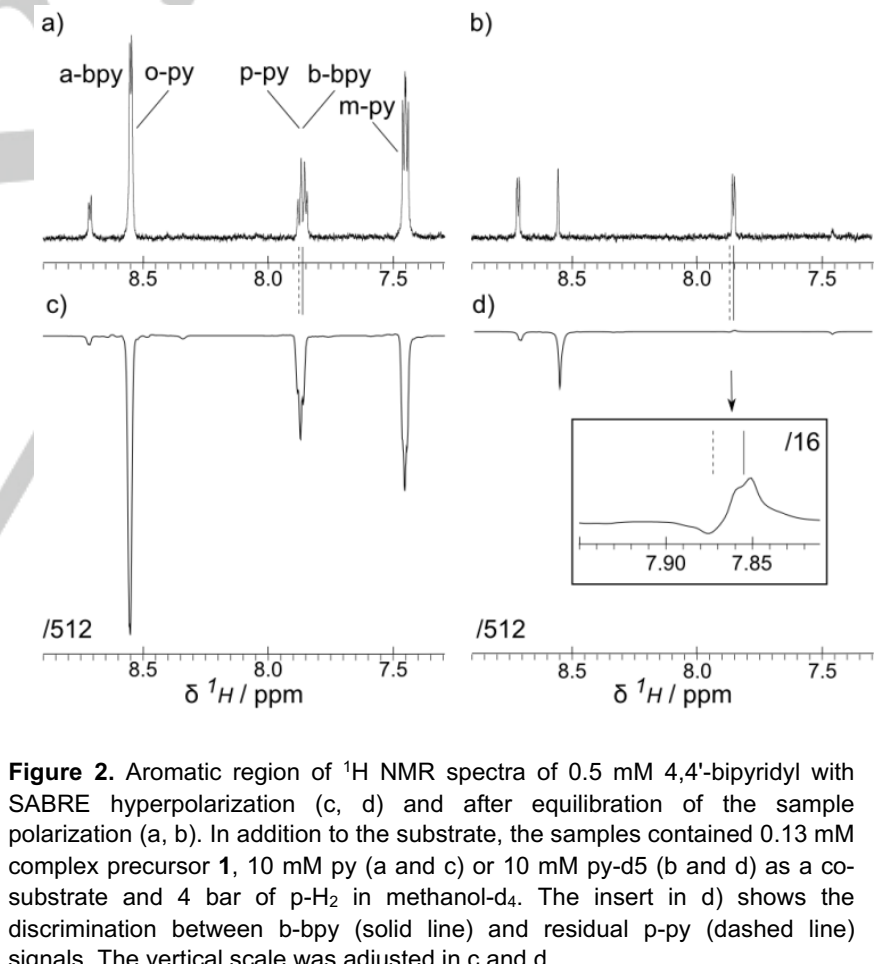

b)

d)

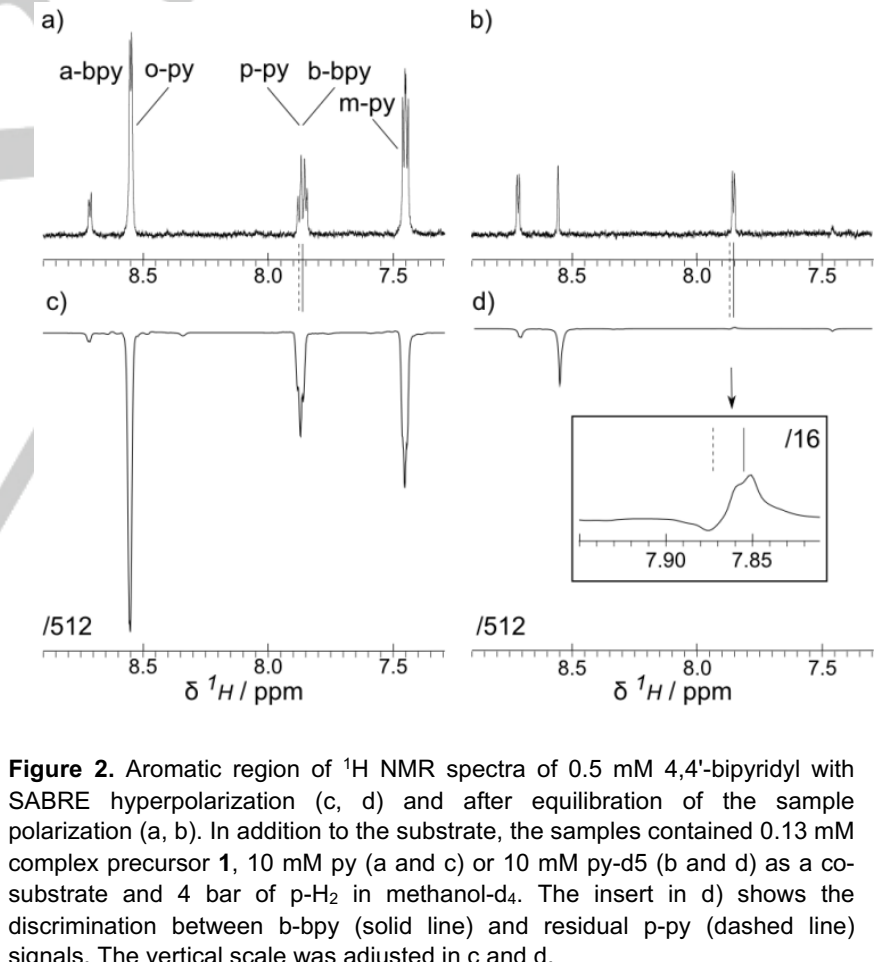

1512

Figure 2. Aromatic region of ${ }^{1} \mathrm{H}$ NMR spectra of $0.5 \mathrm{mM} \mathrm{4,4'-bipyridyl} \mathrm{with}$ SABRE hyperpolarization (c, d) and after equilibration of the sample polarization $(a, b)$. In addition to the substrate, the samples contained $0.13 \mathrm{mM}$ complex precursor 1, $10 \mathrm{mM}$ py (a and c) or $10 \mathrm{mM}$ py-d5 (b and d) as a cosubstrate and 4 bar of $\mathrm{p}-\mathrm{H}_{2}$ in methanol- $\mathrm{d}_{4}$. The insert in d) shows the discrimination between b-bpy (solid line) and residual p-py (dashed line) 
substrate at sub-millimolar concentration. In addition, deuteration of the co-substrate removes the overlap issue between the para position of pyridine and the beta positions of bpy. The asymmetry of the ultrafast COSY spectrum might be due to the asymmetric spatial encoding used ${ }^{[27]}$ As ultrafast $2 \mathrm{D}$ NMR suffers from a sensitivity penalty, ${ }^{[28]}$ SABRE hyperpolarization broadens the range of systems that may benefit from the single-scan acquisition of 2D spectra.

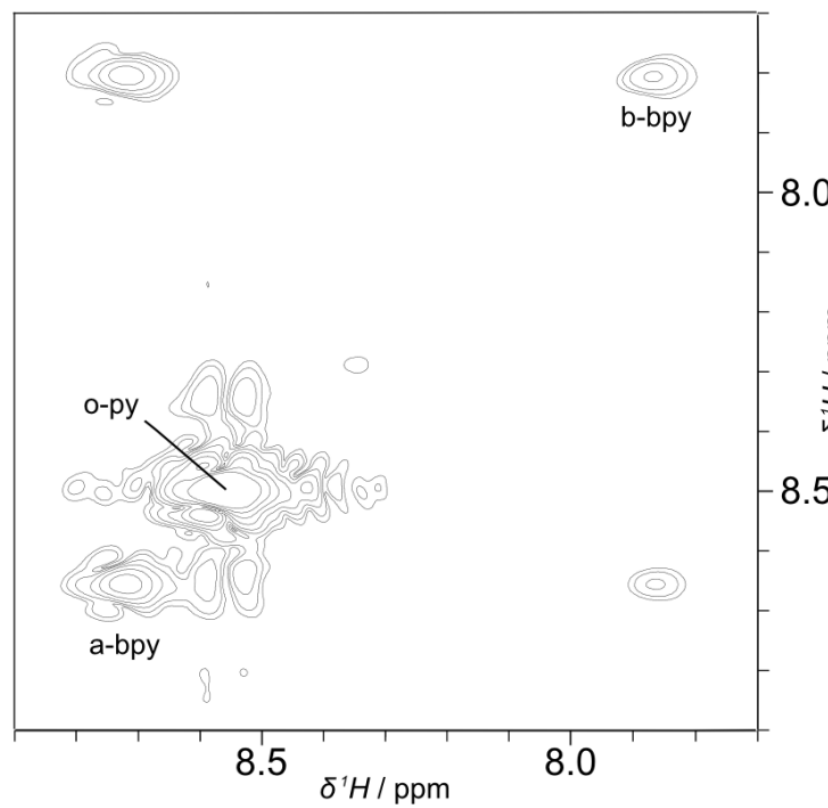

Figure 3. One-scan ultrafast COSY spectrum of $0.5 \mathrm{mM} \mathrm{4,4'-bipyridyl} \mathrm{acquired}$ in less than $1 \mathrm{~s}$, with SABRE hyperpolarization. In addition to the substrate, the sample contained $0.13 \mathrm{mM}$ complex precursor $1,10 \mathrm{mM}$ py- $\mathrm{d}_{5}$ as the cosubstrate and 4 bar of $\mathrm{p}-\mathrm{H}_{2}$ in methanol- $\mathrm{d}_{4}$.

As an illustration of the potential of our approach for obtaining clean, hyperpolarized 2D spectra of low-abundant molecules in a single scan, we analyzed a mixture of small molecules. The mixture consisted of five different substrates, namely bpy, ni, dmni, 2-epy and 3-epy (Fig. 1), all at a concentration on the order of $0.5 \mathrm{mM}$ (see Table S2 for the concentration values). The corresponding ultrafast COSY spectrum (Fig. 4) has a very good quality, especially considering the unfavorable conditions in which it was acquired, i.e. after shaking the NMR tube and without optimized shims. The only molecule not visible is 2-epy, apparently not polarized: this might come from a steric hindrance of the ethyl group in ortho position of the nitrogen atom, which is the bound part of the molecule to the catalyst. ${ }^{[29]}$ For the other molecules, the enhancement factors, estimated from the corresponding 1D SABRE spectrum, are reported in Table S3. Importantly, almost all correlations can be assigned; several of them correspond to resonances that are not resolved in the 1D spectrum, such as 6-ni and a-bpy. In this case, 2D correlations allow full characterization of the mixture. Very few of these correlations are observed when the ultrafast COSY spectrum is recorded at thermal equilibrium (Fig. S2). At such low concentrations, some correlations that are seen in Fig. 4 require an acquisition of several minutes to be observable in a conventional COSY spectrum (Fig. S3). Signal-to-noise ratio has been evaluated to ca. 85 and ca. 7, for the intense correlation 5/4-dmni and the weak correlation 4/2-ni. The presence of high signal-to-noise ratios prompted us to record an ultrafast COSY spectrum at even lower concentrations, less than $0.1 \mathrm{mM}$. It is given in Supporting Information (Fig. S4).

Note that all COSY spectra are displayed here in magnitude mode, as is usual for spatially encoded experiments. ${ }^{[19]}$ While the SABRE process may create multi-spin longitudinal order terms ${ }^{[8]}$ their contribution to the signal is suppressed by the coherence selection gradients.

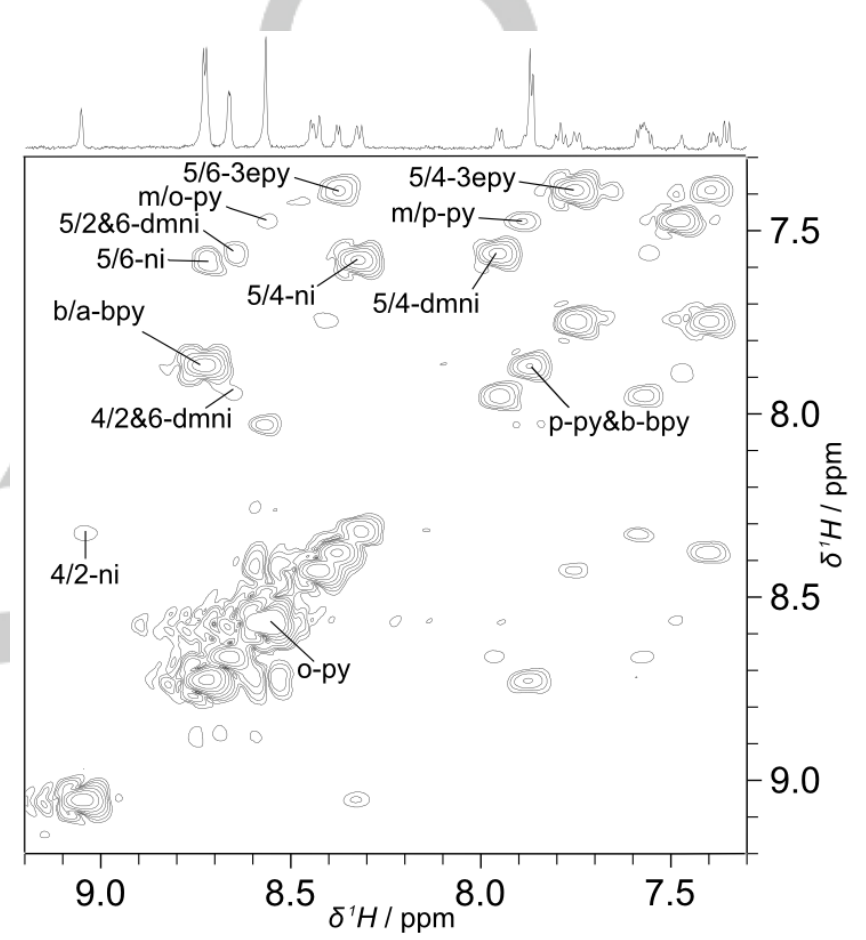

Figure 4. One-scan ultrafast COSY spectrum of a mixture composed by bpy, ni, dmni, 2-epy and 3-epy at concentrations on the order of $0.5 \mathrm{mM}$, with SABRE hyperpolarization. In addition to the substrates, the sample contained $0.13 \mathrm{mM}$ complex precursor $1,10 \mathrm{mM}$ py- $\mathrm{d}_{5}$ as a co-substrate and 4 bar of $p-$ $\mathrm{H}_{2}$ in methanol-d $\mathrm{d}_{4}$. The ultrafast $2 \mathrm{D}$ spectrum was acquired in less than $1 \mathrm{~s}$. The spectrum displayed on top of the 2D map has been recorded in the absence of SABRE hyperpolarization.

Other ultrafast 2D NMR experiments are compatible with SABRE hyperpolarization. In particular, the recently reported direct polarization of ${ }^{15} \mathrm{~N}$ spins ${ }^{[30]}$ should be compatible with HSQC-type experiments ${ }^{[31]}$.

It should be noted that, in the case of a sample mixture, deuteration of the co-substrate again significantly improves the quality of the spectrum, as it removes almost completely interferences by signals of the co-substrate. The isotopic exchange involving protons in ortho position of pyridine-like molecules, however, limits the time scale during which the cosubstrate has minimal contribution to the spectrum. However, this time is sufficient to record good-quality spectra.

\section{Conclusions}


In summary, we have obtained clean, SABRE-hyperpolarized 1D and ultrafast 2D NMR spectra of mixtures of small molecules at low concentrations. It is worth noting that by using a $100 \%$ enriched $\mathrm{p}-\mathrm{H}_{2}$ instead of a $51 \%$ one, enhancements should be increased roughly by a factor of 3 , resulting in decreasing the lower concentration limit by the same factor. This approach could help in the use of hyperpolarized NMR for the analysis of complex mixtures. In particular, ultrafast 2D NMR has been shown to be suitable for quantitative applications ${ }^{[15]}$ and its use for hyperpolarized samples may be assessed for this purpose, for which promising results have been obtained with 1D NMR. ${ }^{[14]}$ Another area of applications is the use of hyperpolarized ligands in binding studies, which can stimulate the screening and discovery of new drugs ${ }^{[32]}$. Obviously, further improvements in the detection threshold will be obtained with the use of a higher enrichment of hydrogen in the para isomer.

\section{Experimental Section}

\section{Chemicals}

Complex precursor $\quad[\operatorname{Ir}(\mathrm{COD})(\mathrm{IMes}) \mathrm{Cl}] \quad$ (1) $\quad(\mathrm{IMes}=1,3-\mathrm{bis}(2,4,6-$ trimethylphenyl)imidazole-2-ylidene, $\quad \mathrm{COD}=$ cyclooctadiene) was purchased from the Centre for Hyperpolarization in MRI of the University of York (UK). Pyridine (py), 4,4'-bipyridyl (bpy), nicotinamide (ni), N,Ndimethylnicotinamide (dmni), 2-ethylpyridine (2-epy), 3-ethylpyridine (3epy) and 4-ethylpyridine (4-epy) were purchased from Sigma-Aldrich. Methanol- $\mathrm{d}_{4}$, pyridine- $\mathrm{d}_{5}\left(\mathrm{py}-\mathrm{d}_{5}\right)$ and 3 -(trimethylsilyl)propionic-2,2,3,3- $\mathrm{d}_{4}$ acid sodium salt (TSP-d $\mathrm{d}_{4}$ ) were purchased from Cambridge Isotope Laboratories. All chemicals are used as supplied. Relevant proton chemical shifts are provided in Table S1.

Para-hydrogen $\left(\mathrm{p}-\mathrm{H}_{2}\right)$ was produced by cooling normal hydrogen down to $77 \mathrm{~K}$ in the presence of hydrous ferric oxide (Molecular Products, Inc.). The resulting $51 \% \mathrm{p}-\mathrm{H}_{2}$, this percentage being controlled by Raman spectroscopy with experimental error of $2 \%$, was transported to a glass container: in the absence of paramagnetic impurities, this percentage of $\mathrm{p}-\mathrm{H}_{2}$ remains stable for several hours.

\section{Protocol and NMR experiments}

All spectra were acquired at room temperature with a Bruker AVANCE II $600 \mathrm{MHz}$ spectrometer operating at $599.82 \mathrm{MHz}$ and equipped with an unshielded Oxford magnet and a $5 \mathrm{~mm} \mathrm{TCl}$ cryo-cooled probe. Samples were collected into $5 \mathrm{~mm}$ Young pressure valve NMR tubes and degassed through two freeze-pump-thaw cycles. $1 \mathrm{mM}$ of TSP-d $\mathrm{d}_{4}$ was added into each sample as a concentration reference.

A few minutes after its preparation, $\mathrm{p}-\mathrm{H}_{2}$ was introduced at a pressure of ca. 4 bar and the sample was vigorously shaken for several seconds, in order to saturate the solution, allowing the formation of metal complexes $\left[\operatorname{lr}(\mathrm{IMes})(\mathrm{H})_{2}\left(\mathrm{~S}_{\mathrm{i}}\right)\left(\mathrm{S}_{\mathrm{j}}\right)\left(\mathrm{S}_{\mathrm{k}}\right)\right] \mathrm{Cl}(\mathbf{2})$ via hydrogenation of the COD ligand of 1.

After full activation, checked by monitoring the saturation of the cyclooctane signal intensity, the volume above the solution was evacuated and $\mathrm{p}-\mathrm{H}_{2}$ was introduced at a pressure of ca. 4 bar. Samples were shaken for 15 seconds at a fixed position in the stray field of the spectrometer, resulting in polarization transfer field strength of approximately $7 \mathrm{mT}$. This magnetic field has been shown to be optimal for pyridine. ${ }^{[22]}$, although recent simulations performed in continuous re- hyperpolarization suggest an optimum at $5.5 \mathrm{mT} .{ }^{[33]}$ Obviously the optimum may be different for each substrate. As the magnet is not actively shielded, the sample experiences limited magnetic field gradient during this step. The sample was then rapidly inserted into the bore; then a $90^{\circ}$ rf pulse was applied to obtain a SABRE spectrum ca. $8 \mathrm{~s}$ after the end of the shaking step. Reference spectra for signal enhancement determination were recorded in quantitative conditions, i.e. with a prescan delay of at least 5 times the longest proton longitudinal relaxation times, and at least 10 minutes after the SABRE experiments. Signal enhancements were obtained by dividing the integrals of the SABRE signals by the corresponding ones on the reference spectra. Signal-tonoise ratios were estimated from the sino function of Topspin 3.2 software, applied to rows and columns at maximum height of the chosen correlations.

The ultrafast COSY sequence, described elsewhere, ${ }^{[18,34]}$ is reported in figure S1. Spatial encoding was performed using a constant-time encoding scheme. ${ }^{[26]}$ Smoothed chirp encoding pulses of $15 \mathrm{~ms}$ with a sweep width of $8 \mathrm{kHz}$ were applied for spatial encoding. The amplitude of the spatial encoding gradients $\mathrm{G}_{\mathrm{e}}$ was $0.8 \mathrm{G} / \mathrm{cm}$. The amplitude of the coherence selection gradients before and after the mixing pulse was 43.2 $\mathrm{G} / \mathrm{cm}$ with a duration of $1.25 \mathrm{~ms}$. The anti-echo gradient $\mathrm{G}_{p}$ consisted of a $0.3 \mathrm{~ms}$ sine-bell gradient of maximal intensity $16.2 \mathrm{G} / \mathrm{cm}$. Acquisition gradients $G_{a}$ of duration $312.8 \mu$ s and strength $32.4 \mathrm{G} / \mathrm{cm}$ were used. 128 gradients pairs $\left\{\mathrm{G}_{a} ;-\mathrm{G}_{\mathrm{a}}\right\}$ were used during acquisition. Ultrafast $2 \mathrm{D}$ spectra were processed with the ufproc program provided by the University of Nantes. ${ }^{[35]}$

\section{Acknowledgements}

We thank Hana Kourilova, Bruno Coltrinari and Estelle Léonce for help with the setup of parahydrogen experiments. Support from the CEA Nanosciences program is acknowledged (HYPARE Project). We thank the EBSI group from the University of Nantes for providing tools for the acquisition and processing of NMR spectra.

Keywords: analytical methods $\cdot$ hyperpolarization $\cdot$ NMR spectroscopy $\cdot$ para-hydrogen $\cdot$ ultrafast experiments

[1] R. A. Green, R. W. Adams, S. B. Duckett, R. E. Mewis, D. C. Williamson, G. G. R. Green, Prog. Nucl. Magn. Reson. Spectrosc. 2012, 67, 1-48.

[2] C. R. Bowers, D. P. Weitekamp, Phys Rev Lett 1986, 57, 2645-2648.

[3] C. R. Bowers, D. P. Weitekamp, J. Am. Chem. Soc. 1987, 109, 5541-5542.

[4] J.-B. Hövener, E. Chekmenev, K. Harris, W. Perman, L. Robertson, B. Ross, P. Bhattacharya, Magn. Reson. Mater. Phys. Biol. Med. 2009, 22, 111-121.

[5] J.-B. Hövener, S. Baer, J. Leupold, K. Jenne, D. Leibfritz, J. Hennig, S. B. Duckett, D. von Elverfeldt, NMR Biomed. 2013, 26, 124-131.

[6] K. D. Atkinson, M. J. Cowley, S. B. Duckett, P. I. P. Elliott, G. G. R. Green, J. Lopez-Serrano, I. G. Khazal, A. C. Whitwood, Inorg Chem 2009, 48.

[7] R. W. Adams, J. A. Aguilar, K. D. Atkinson, M. J. Cowley, P. P. Elliott, S. B. Duckett, G. G. R. Green, I. G. Khazal, J. López-Serrano, D. Williamson, Science 2009, 323, 1708-1711.

[8] R. W. Adams, S. B. Duckett, R. A. Green, D. C. Williamson, G. G. R. Green, $J$ Chem Phys 2009.

[9] H. Zeng, J. Xu, J. Gillen, M. T. McMahon, D. Artemov, J.-M. Tyburn, J. A. B. Lohman, R. E. Mewis, K. D. Atkinson, G. G. R. Green, et al., J. Magn. Reson. 2013, 237, 73-78.

[10] M. F. Murray, Clin. Infect. Dis. 2003, 36, 453-460.

[11] N. Eshuis, N. Hermkens, B. J. A. van Weerdenburg, M. C. Feiters, F. P. J. T. Rutjes, S. S. Wijmenga, M. Tessari, J. Am. Chem. Soc. 2014, 136, 2695-2698.

[12] R. E. Mewis, R. A. Green, M. C. R. Cockett, M. J. Cowley, S. B. Duckett, G. G. R. Green, R. O. John, P. J. Rayner, D. C. Williamson, J. Phys. Chem. B 2015, 119, 1416-1424.

[13] E. B. Dücker, L. T. Kuhn, K. Münnemann, C. Griesinger, J. Magn. Reson. 2012, $214,159-165$. 
[14] N. Eshuis, B. J. A. van Weerdenburg, M. C. Feiters, F. P. J. T. Rutjes, S. S. Wijmenga, M. Tessari, Angew. Chem. Int. Ed. 2015, 54, 1481-1484.

[15] P. Giraudeau, Magn. Reson. Chem. 2014, 52, 259-272. [16] L. Frydman, T. Scherf, A. Lupulescu, Proc. Natl. Acad. Sci. 2002, 99, 15858-

[17] L. Frydman, A. Lupulescu, T. Scherf, J. Am. Chem. Soc. 2003, 125, 9204-9217.

[18] M. Pathan, S. Akoka, I. Tea, B. Charrier, P. Giraudeau, Analyst 2011, 136, 3157-3163.

[19] P. Giraudeau, L. Frydman, Annu. Rev. Anal. Chem. 2014, 7, 129-161.

[20] L. S. Lloyd, R. W. Adams, M. Bernstein, S. Coombes, S. B. Duckett, G. G. R Green, R. J. Lewis, R. E. Mewis, C. J. Sleigh, J. Am. Chem. Soc. 2012, 134, 12904-12907.

[21] L. S. Lloyd, Developing SABRE as an Analytical Tool in NMR, University of York, 2013

[22] M. J. Cowley, R. W. Adams, K. D. Atkinson, M. C. R. Cockett, S. B. Duckett, G. G. R. Green, J. A. B. Lohman, R. Kerssebaum, D. Kilgour, R. E. Mewis, J. Am. Chem. Soc. 2011, 133, 6134-6137.

[23] J. A. Brown, S. Irvine, A. R. Kennedy, W. J. Kerr, S. Andersson, G. N. Nilsson, Chem Commun 2008, 1115-1117.

[24] G. N. Nilsson, W. J. Kerr, J. Label. Compd. Radiopharm. 2010, 53, 662-667.

[25] D. A. Barskiy, K. V. Kovtunov, I. V. Koptyug, P. He, K. A. Groome, Q. A. Best, F. Shi, B. M. Goodson, R. V. Shchepin, A. M. Coffey, et al., J. Am. Chem Soc. 2014, 136, 3322-3325.
[26] P. Pelupessy, J. Am. Chem. Soc. 2003, 125, 12345-12350.

[27] B. Shapira, Y. Shrot, L. Frydman, J. Magn. Reson. 2006, 178, 33-41.

[28] A. Tal, L. Frydman, Prog. Nucl. Magn. Reson. Spectrosc. 2010, 57, 241-292.

[29] R. V. Shchepin, M. L. Truong, T. Theis, A. M. Coffey, F. Shi, K. W. Waddell, W. S. Warren, B. M. Goodson, E. Y. Chekmenev, J. Phys. Chem. Lett. 2015, 6, 1961-1967.

[30] T. Theis, M. L. Truong, A. M. Coffey, R. V. Shchepin, K. W. Waddell, F. Shi, B. M. Goodson, W. S. Warren, E. Y. Chekmenev, J. Am. Chem. Soc. 2015, 137, 1404-1407.

[31] L. Frydman, D. Blazina, Nat Phys 2007, 3, 415-419.

[32] Y. Lee, H. Zeng, A. Mazur, M. Wegstroth, T. Carlomagno, M. Reese, D. Lee, S. Becker, C. Griesinger, C. Hilty, Angew. Chem. Int. Ed. 2012, 51, 5179-5182.

[33] J.-B. Hövener, S. Knecht, N. Schwaderlapp, J. Hennig, D. von Elverfeldt, CHEMPHYSCHEM 2014, 15, 2451-2457.

[34] A. Le Guennec, I. Tea, I. Antheaume, E. Martineau, B. Charrier, M. Pathan, S. Akoka, P. Giraudeau, Anal. Chem. 2012, 84, 10831-10837.

[35] P. Giraudeau, B. Charrier, S. Akoka, Univ. of Nantes, http://madoc.univnantes.fr/course/view.php?id=24710 
Entry for the Table of Contents (Please choose one layout)

Layout 1:

\section{ARTICLE}

Here we describe an approach to obtain clean, SABRE-hyperpolarized 1D and 2D NMR of mixtures of small molecules in a single scan. By relying on a deuterated co-substrate together with ultrafast 2D NMR sequences, the discrimination of molecules at sub-millimolar concentrations can be achieved.

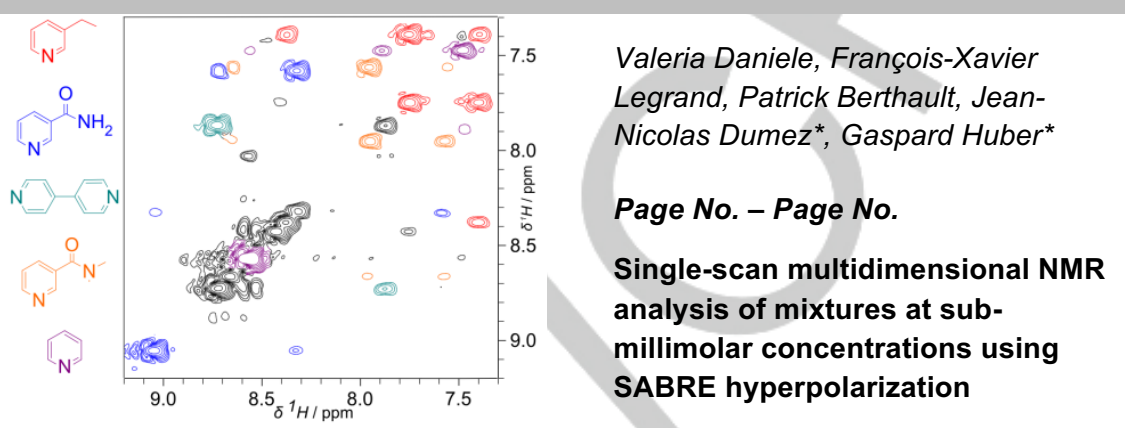

Single scan with $0.5 \mathrm{mM}$ concentration 